\title{
Assessing the effect of barns structures and environmental conditions in dairy cattle farms monitored in Northern Italy
}

\author{
Daniela Lovarelli, ${ }^{1}$ Elisabetta Riva, ${ }^{2}$ Gabriele Mattachini, ${ }^{2}$ Marcella Guarino, ${ }^{1}$ Giorgio Provolo ${ }^{2}$ \\ ${ }^{1}$ Department of Environmental Science and Policy; and ${ }^{2}$ Department of Agricultural and Environmental Sciences, \\ Università degli Studi di Milano, Milano, Italy
}

\begin{abstract}
Animal welfare is a fundamental pillar for livestock farming, and it can be endangered by a series of aspects, among which is the presence of undesired microclimates. This condition can be monitored by measuring the temperature-humidity index (THI), an index able to inform about the emergence of heat-stressing conditions in the barns. The THI can be influenced by the external environmental conditions and the barn structure, orientation, thermal buoyancy, and roof insulating materials. In order to evaluate these structural aspects of buildings and the consequent microclimate, in this study, a survey was carried out in 8 dairy cattle barns located in the northern part of Italy that were monitored continuously during thermoneutral, warm, and cold periods. Experts observed the structural aspects , and the environmental parameters were measured with sensors. From the results emerged that the barns had structural characteristics that considerably affect the internal microclimate, with openings, roof height, forced ventilation, and building orientation playing a significant role in estimating of the THI in the barn. The more critical period was the warm one when the structures could not mitigate the external conditions, and THI exceeded the threshold of 72 for a big share of the period in all monitored farms (range between $50-80 \%$ of observations). In the best situation, the cooling systems were able to maintain the external conditions. The results confirm the importance of the barn design and of an appropriate ventilation to improve air exchanges.
\end{abstract}

Correspondence: Daniela Lovarelli, Department of Environmental Science and Policy, Università degli Studi di Milano, 20133 Milano, Italy. E-mail: daniela.lovarelli@unimi.it

Key words: Barn; dairy cows; microenvironment; ventilation; temperature-humidity index.

Funding: this research was funded by the Italian Ministry of Education, University and Research in Research projects of relevant national interest. Grant number 20178AN8NC. 'Smart Dairy Farming - Innovative solutions to improve herd productivity'.

Received for publication: 12 July 2021.

Accepted for publication: 27 September 2021.

${ }^{\circ}$ Copyright: the Author(s), 2021

Licensee PAGEPress, Italy

Journal of Agricultural Engineering 2021; LII:1229

doi:10.4081/jae.2021.1229

This article is distributed under the terms of the Creative Commons Attribution Noncommercial License (by-nc 4.0) which permits any noncommercial use, distribution, and reproduction in any medium, provided the original author(s) and source are credited.

\section{Introduction}

In intensive livestock systems, the reared animals commonly live lifelong in a confined environment; therefore, it is of fundamental importance that the barn is built adequately to respond to their needs (Fernández et al., 2008). These needs principally depend on the reared species, metabolism, management operations, welfare requirements, and local climate. Safe environments and optimal welfare conditions are prerequisites for healthy and productive animals (Polsky and von Keyserlingk, 2017) and consequently also for overall sustainable productions (Halachmi et al., 2019; Lovarelli et al., 2020a). However, because of the global warming and increase of temperatures, all reared animal species can be endangered in the current decades by an intensification of heat stressing events that affect health, welfare, and productivity (Hempel et al., 2019).

Focusing on dairy cattle, building adequate barns to respond to local environmental issues is essential (Berman, 2019). Dairy cattle have optimal performances in thermally neutral conditions (from about -5 to $25^{\circ} \mathrm{C}$ and 45 to $90 \%$ relative humidity) (CIGR, 2014), generally measured through the temperature-humidity index (THI). THI is calculated with temperature and relative humidity data collected in the barn and should be optimally maintained below 72 (Allen et al., 2015), although some authors identified heat stress starting already with THI $>68$ (Polsky and von Keyserlingk, 2017). Exceeding this threshold leads to significant production losses, quantified in $10-35 \%$ reductions already with temperatures higher than $24^{\circ} \mathrm{C}$ or relative humidity higher than $70-75 \%$ (Bohmanova et al., 2007). In addition, altered animal behaviour such as different feed and water intake, affective state and life naturalness (Polsky and von Keyserlingk, 2017), and health and reduced fertility are monitored with excessive THI (Das et al., 2016). In Northern Europe, Russia, Canada, etc., where winter is very harsh, cattle are reared in closed buildings that protect them from excessive cold. However, at lower latitudes and temperate climates such as in South and Central Europe, cows suffer frequently from warm temperatures (Hempel et al., 2018); therefore, livestock barns are primarily open and have lateral and ridge openings to favour the natural ventilation and air exchanges, and reduce relative humidity. Natural ventilation (e.g., thermal buoyancy and wind action) is by far the most widespread solution for dairy cattle housing (CIGR, 2014; Tomasello et al., 2019) when it is sufficient to maintain good air quality. Besides having windows and doors, the ridge openings are important structural solutions that, if properly built, permit the correct air movements and thermal buoyancy. These last improve air exchange rates and air quality (e.g., removal of pollutants such as methane and ammonia, removal of dust, and reduction of moisture that makes air heavier and promotes bacterial growth) (Bagdoniene and Bleizgys, 2014). A suitable height and width of the ridge opening guarantees that the air incoming from windows and lateral open- 
ings runs into the barn and exits from the roof involving proper air exchanges (De Paepe et al., 2012). In the study by De Paepe et al. (2012), authors showed that an enlarged inlet opening height or a completely removed front wall does not affect the air exchange rate as much as a wholly removed outlet wall can. Furthermore, air exchanges can be favoured by the barn orientation. The longitudinal orientation of the building east-west $(\mathrm{E}-\mathrm{W})$ is the best since it reduces the exposition to solar radiation because the two long walls are, in turn, exposed to the sun during the day (CIGR, 2014); moreover, this different exposition brings a temperature difference on the two long walls that favours the natural ventilation of the building (thermal buoyancy). The proper orientation should also consider the predominant wind direction. After all, an appropriate wind circulation (guaranteed by a perpendicular orientation with the predominant wind direction) favours the internal air exchanges (Firfiris et al., 2019). Finally, the insulation material of walls and roofs is another key element that influences the radiant heat load and the thermal balance of animals (Berman, 2019). As shown in Firfiris et al. (2019), there is wide variability in materials and thicknesses to be used with different insulating capabilities and costs. Menconi and Grohmann (2014) realized a life cycle cost (LCC) analysis showing that the most expensive and cheap materials were polyurethane (best temperature control but high primary energy cost) and glass wool, respectively. According to Firfiris et al. (2019), the best solutions are glass wool or expanded polystyrene.

Considering all these structural aspects and the need for a safe environment, properly building a barn is quite complex (Fernández et al., 2008; CIGR, 2014). In fact, in each farm, there can be a series of alternatives to consider when building a new barn and retrofitting already existing buildings. Aspects such as the local climate and the barn orientation can lead forcefully to defined decisions (Firfiris et al., 2019). When an existing building needs to be improved, some suggestions include, for example, the planting of trees in the surroundings or the installation of green roofs with a shading effect and support in dealing with air pollutants (Bar et al., 2019; Berman, 2019). Shaded areas can also help with animal welfare (Van Iaer et al., 2015) and maintain adequate respiration rates during hot periods (Das et al., 2016). A complement to these is forced ventilation, an effective and immediate solution to reduce heat-stressing conditions when no structural improvements can be introduced or are not economically sustainable. Forced ventilation involves the installation of fans that induce air movements in the barn and favour air exchanges, thus limiting the effects of excessive relative humidity and metabolic heat releases and reducing cows' body temperatures. Forced ventilation is becoming more common in many countries, among which in Italy, where summer heatwaves are putting much pressure on cattle health and performances (Porto et al., 2017; Berman, 2019). Fogging and/or sprinkler systems can be added to the standard circulation fans and ceiling fans. Using water to cool air or wet animals' skin is an effective practice (Firfiris et al., 2019). However, the disadvantage is related to the initial investment, maintenance, and high water and electricity consumption that represent both an economic and environmental cost (e.g., climate change, use of non-renewable resources, etc.) (Polsky and von Keyserlingk, 2017). In particular, fogging systems need high pressures to nebulize water that evaporates and cools air temperature (De Paepe et al., 2012), while sprinklers directly wet animals' skin, involving much higher water consumption at lower pressure, finally resulting in more effective in cooling the microenvironment. Berman (2019) showed the beneficial effect of combining forced ventilation with wetting cows' bodies to increase the convective heat loss of animals but underlying the need to pay attention to slippery wet floors. Moreover, Pinto et al. (2019) tested different frequencies for ventilation systems, reporting the beneficial effects on the respiration rate when ventilation was turned on more frequently. Honig et al. (2012) achieved the same results, identifying benefits on welfare and behaviour (lying and ruminating time) when forced ventilation worked frequently. Finally, Porto et al. (2017) compared two cooling systems from which emerged that the fogging system installed in the lying area guaranteed the lying time, while the sprinkler system in the feeding area had no influence on the standing time and a low influence on the feeding activity.

Although a posteriori interventions to improve air exchanges can be considered effective, the starting point should be the proper barn building. Therefore, in this study, a survey was carried out in 8 dairy cattle farms in Northern Italy that are typical for the area, where structural characteristics were observed, and the environmental conditions inside and outside the barns were studied. This study aims to demonstrate the influence of the structure on the internal microclimate of dairy cattle barns to maintain proper environmental conditions for cows' welfare.

\section{Materials and methods}

In Northern Italy, and more precisely in the Lombardy region, about $33 \%$ of Italian dairy cattle are reared (ISTAT, 2021). The livestock farms are relatively homogeneously distributed in most of the provinces of the region: in Milan (8\%), Bergamo $(17 \%)$, Brescia (8\%), Pavia (14\%), Cremona (14\%), and Lodi (16\%) and the average herd dimension is 101 dairy cows/farm (i.e., 65 dairy cows in production stage/farm). In the context of the Prin Project 'Smart Dairy Farming: Innovative solutions to improve herd productivity', eight dairy cattle barns were selected to be thoroughly monitored for one year. Among the criteria to choose the farms were the farmers' availability to the monitoring and the identification of farms that could be paired at short distances to reduce the effect of any external parameter that could affect the single microclimate of the barn. Hence, were selected livestock farms located in Brescia (farms A and B), Cremona (farms C and D), Lodi and Pavia (farms E and F), and Cremona and Brescia (farms $\mathrm{G}$ and $\mathrm{H}$ ). The last two groupings show farms in different provinces but in such a position that their distances are maintained within a few kilometres $(5-15 \mathrm{~km})$. The farms showed some variability in terms of bred animals, counting an average of $88 \pm 38$ monitored cows/barn and bred almost entirely Italian Holstein dairy cows. The farms were grouped in pairs on both a geographical basis (i.e., short distances for paired farms) and a temporal one for the monitoring (i.e., same monitoring week for the paired farms). In other words, the available instrumentation allowed monitoring the paired farms contemporarily.

The monitoring lasted for one year, in which thermoneutral, warm, and cold periods were surveyed. Every survey lasted one week, during which environmental data about the microclimate in the barn were collected continuously. Moreover, the cows' lying activity was measured through pedometers installed on the hind leg of cows as described in Lovarelli et al. (2020b), and cows' productivity was measured through the daily average milk production. The observations took place from $15^{\text {th }} \mathrm{Jan}$. to $25^{\text {th }} \mathrm{Feb}$. (cold period), from $16^{\text {th }}$ Apr. to $24^{\text {th }}$ May and $23^{\text {rd }}$ Oct. to $30^{\text {th }}$ Oct. (thermally neutral period), and from $2^{\text {nd }}$ Jul. to $7^{\text {th }}$ Aug. (hot period). A visit was carried out at every farm at the beginning (day 1) and at the end (day 7) of each survey; thus, 6 visits per farm were done in 
one year. During the first visit, the barn structure, dimension, orientation, and ventilation systems were observed to have a complete and clear understanding of the main structural characteristics and livestock management. In addition, the environmental sensors were installed and then uninstalled on day 7 of each survey.

The environmental data were collected using sensors to measure the air temperature $\left(\mathrm{T},{ }^{\circ} \mathrm{C}\right)$ and relative humidity $(\mathrm{RH}, \%)$. These sensors (HOBO U12 Temp/RH/Light/External Data Logger - Onset Computer Corporation, Bourne, MA, USA) were installed in 2 positions at the height of about 2 meters in one part of the barn and recorded data every half hour, thus having 24 h-7 d data. In addition, local weather conditions were investigated by downloading from the Regional Environmental Protection Agency (ARPA) of Lombardy Region website the hourly average temperature and relative humidity of the ground-based weather station closest to each farm. Although the weather stations were not on the farm, they were pretty close, so it was assumed that minor differences could be found with the effective weather on the farm; the same method was presented in Tomasello et al. (2019). With these data, THI was quantified with the equation suggested by ASABE (ASABE, 2006), both in the barn (microclimate) and outside the barn (external weather conditions). To analyse the differences of barn structures and microclimate, and evaluate the difference between inside and outside, were calculated daily: i) deltaT $\left({ }^{\circ} \mathrm{C}\right)$, i.e., the difference between average internal temperature and external temperature; ii) deltaRH (\%), i.e., the difference between internal and external average relative humidity; iii) deltaTHI, i.e., the difference between internal and external average THI.

The data analysis was carried out using the software SAS 9.4 (TS1M3, 2012, SAS Inst. Inc. Cary, NC). First, descriptive statistics were carried out; then, using the Proc FASTCLUS procedure, hourly data were clustered concerning the external THI, which allowed comparing farms considering their similar external weather conditions. In a third step, classes of internal THI were built using hourly data to evaluate in detail the THI in the different barns and the different clusters. Therefore, 6 classes were built based on the internal THI and focused on the warm conditions. In particular, all THI values below 58 were included in a first class with low THI data (class (i) THI <=58). Then, an intermediate class in which no stress occurs was considered (class (ii) THI 58-69), and then the other classes included very small ranges of THI, first with the class (iii) 69-72 that highlights the emergence of stressing conditions and then the other more alarming and dangerous classes, following Provolo and Riva (2008): (iv) 72-75, (v) 75-78, (vi) $>78$. According to CIGR (2014) and Polsky and von Keyserlingk (2017), the first signals of heat stress can be observed from a THI value equal to 69 , especially for the most productive and sensitive cows. This is the reason why this value was included in the classes.

Finally, the Proc GLM (generalized linear model procedure) was done to build a model predicting the variable of the THI in the barn and evaluate the effect of a series of structural parameters on the proper design of a dairy cattle barn. The model used a series of class variables: i) the clusters previously formed with Proc Fastclus (3 levels: $<\mathrm{N}, \mathrm{W}, \mathrm{C})$; ii) the presence of lateral openings (2 levels: yes, partially); iii) the roof height (2 levels: medium - if between 7-14 m, low - if less than $7 \mathrm{~m}$ ); iv) ventilation system (3 levels: in the feeding area, in resting area, in both); and v) barn orientation (3 levels: E-W, NW-SE, and NE-SW). For all the parameters included in the model, LSMeans were also calculated.

\section{Results and discussion}

\section{Barns structures}

Table 1 reports the characteristics of barn structures, dimensions, orientation, and ventilation studied during the first visit to the farms. In addition, also the main herd information (average milk production, average lying time, and bedding materials in cubicles) is reported. For herd information, the monitored cows had an average milk production within the ranges of local farms' productivity: on average, farm D was the most productive (41 kg/d per cow), while farm E was the least productive ( $29 \mathrm{~kg} / \mathrm{d}$ per cow). Similar productivity data can be found in other studies in Northern Italy, where average milk production was lower than or about 30

Table 1. Herd and building information (barn and cooling system) for each farm.

\begin{tabular}{|c|c|c|c|c|c|c|c|c|c|c|c|c|c|c|c|}
\hline \multirow{2}{*}{ Farm } & \multicolumn{5}{|c|}{ Herd information } & \multicolumn{7}{|c|}{ Barn information } & \multicolumn{3}{|c|}{ Cooling system } \\
\hline & $\begin{array}{l}\text { Monitored } \\
\text { cows } \\
\text { (n.)* }\end{array}$ & $\begin{array}{l}\text { Milk prod. } \\
\text { (kg/d) }\end{array}$ & $\begin{array}{l}\text { Lying } \\
\text { time } \\
(\mathrm{h})^{\circ}\end{array}$ & $\begin{array}{l}\text { Bedding } \\
\text { material }\end{array}$ & $\begin{array}{c}\text { Barn } \\
\text { orientation }\end{array}$ & $\begin{array}{c}\text { Barn } \\
\text { surface } \\
\left(\mathrm{m}^{2}\right)^{\circ}\end{array}$ & $\begin{array}{c}\text { Roof } \\
\text { insulation }\end{array}$ & $\begin{array}{l}\text { Ridge } \\
\text { height } \\
\text { (m) }\end{array}$ & $\begin{array}{l}\text { Roof } \\
\text { slope } \\
(\%)\end{array}$ & $\begin{array}{l}\text { Ridge } \\
\text { opening }\end{array}$ & $\begin{array}{l}\text { Lateral } \\
\text { opening }\end{array}$ & $\begin{array}{l}\text { Shading } \\
\text { system }\end{array}$ & $\begin{array}{l}\text { Feeding } \\
\text { area }\end{array}$ & $\begin{array}{l}\text { Resting } \\
\text { area }\end{array}$ & $\begin{array}{c}\text { Wait/milking } \\
\text { area }\end{array}$ \\
\hline A & 60 & 30.9 & 10.5 & Straw & E-W & 672 & Yes & 7 & 23 & N.P. & Partial & Curtains & $\begin{array}{l}\text { Circ. fans + } \\
\text { fogging }\end{array}$ & Circ. fans & Fans + fogging \\
\hline B & 106 & 32 & 10.1 & Straw & NW-SE & 1288 & No & 12.2 & 28 & $\begin{array}{l}\text { Adequate } \\
\qquad(1 \mathrm{~m})\end{array}$ & Partial & Walls & $\begin{array}{l}\text { Circ. fans + } \\
\text { fogging }\end{array}$ & N.P. & Fans \\
\hline C & 72 & 32 & 10.9 & Mattr. & E-W & 902 & No & 6.5 & 11 & N.P. & Partial & Walls & N.P. & Ceiling fans & N.P. \\
\hline D & 144 & 41 & 11.7 & Mattr. & NE-SW & 1162 & Yes & 7.7 & 15 & $\begin{array}{l}\text { Adequate } \\
(1.3 \mathrm{~m})\end{array}$ & Partial & Curtains & $\begin{array}{l}\text { Circ. fans + } \\
\text { sprinkler }\end{array}$ & N.P. & N.P. \\
\hline $\mathrm{E}$ & 35 & 29 & 9.8 & Mattr. & NW-SE & 562 & Yes & 7 & 13 & $\begin{array}{l}\text { Adequate } \\
(1.9 \mathrm{~m})\end{array}$ & Yes & Partial walls & Sprinkler & Ceiling fans & Fans \\
\hline $\mathrm{F}$ & 143 & 32 & 11.2 & Straw & NW-SE & 3640 & Yes & 13.4 & 33 & $\begin{array}{l}\text { Adequate } \\
(0.8 \mathrm{~m})\end{array}$ & Partial & Curtains & N.P. & Ceiling fans & Fans \\
\hline G & 54 & 32 & 11.3 & Sand & NW-SE & 1242 & Yes & 5.4 & 13 & $\begin{array}{l}\text { Adequate } \\
(0.5 \mathrm{~m})\end{array}$ & Yes & Curtains & Sprinkler & $\begin{array}{l}\text { Ceiling fans + } \\
\text { sprinkler }\end{array}$ & Fans \\
\hline $\mathrm{H}$ & 88 & 35.5 & 11.7 & Mattr. & E-W & 1440 & Yes & 7.5 & 10 & $\begin{array}{l}\text { Insuff. } \# \\
(0.2 \mathrm{~m})\end{array}$ & Partial & Curtains & $\begin{array}{c}\text { Circ. fans + } \\
\text { sprinkler }\end{array}$ & Circ. fans & N.P. \\
\hline
\end{tabular}

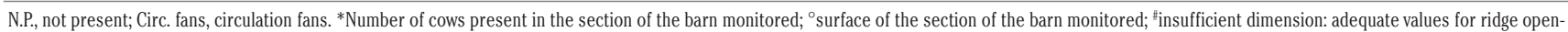
ing consist in ridges of at least $0.05 \mathrm{~m}$ wide every $3 \mathrm{~m}$ of barn width. Source Lovarelli et al., 2020b. 
$\mathrm{kg} / \mathrm{d}$ per cow (Bellingeri et al., 2019). Regarding the bedding material, mattresses and straw were the two most frequently chosen solutions, one because it is a hygienic solution, the other because it facilitates manure handling and management (Ferraz et al., 2020).

Regarding the structure, all farms in this study had a good longitudinal barn orientation, with farms $\mathrm{A}, \mathrm{C}$, and $\mathrm{H}$ oriented $\mathrm{E}-\mathrm{W}$, and the other 5 farms oriented NW-SE or NE-SW. Although presenting the best orientation, farms $\mathrm{A}$ and $\mathrm{C}$ lacked the ridge opening, and farm $\mathrm{H}$ had an insufficient dimension $(<0.2-0.3 \mathrm{~m})$ for air movements (De Paepe et al., 2012). Farms A, B, and F had relatively high roof slopes that facilitate the air exchange rates exploiting natural ventilation, but with no excessive roof inclinations $(>30 \%)$ that may cause unnecessarily high roof temperatures (Vox et al., 2016). Farms $\mathrm{C}$ and $\mathrm{G}$ had a low ridge height $(<7 \mathrm{~m})$ that affected air exchange rates, especially in farm $\mathrm{C}$ with a low roof slope, no ridge opening, and no insulating material on the roof; this last characteristic was in common with farm B. According to Menconi and Grohmann (2014), the lack of insulation can cause increased temperatures inside the barn.

As other systems to improve the microclimate, most farms adopted sidewall curtains on the barn side exposed to the sun in the hottest part of the day to protect from solar radiation (Polsky and von Keyserlingk, 2017). An alternative was the construction of concrete walls (farms B, C, and partially E). Forced ventilation systems were installed in all the studied farms. Circulation fans coupled, in some cases, with fogging or sprinklers, and/or ceiling fans were present in the feeding or lying areas or both areas. In some farms, fans were also installed in the holding and milking parlour areas. Only farms $\mathrm{C}$ and $\mathrm{F}$ did not have any ventilation system in the feeding area, while only farms B and D did not have forced ventilation at lying. Farm $\mathrm{C}$ had the least tools installed.

\section{Environmental conditions}

By running the FASTCLUS Procedure, three clusters were built based on hourly external THI. The resulting expected overall R2 was equal to 0.89 , and the cubic clustering criterion was met (equal to 4.8). The clusters' means and standard deviations resulted in $58.0 \pm 4.7,73.7 \pm 4.7,37.8 \pm 5.6$, respectively, for Cluster 1, 2, and 3. From these results, it can be assumed that Cluster 1 includes observations in thermally neutral conditions, while Cluster 2 comprises warm periods (highest THI) and Cluster 3 those of the coldest periods (lowest THI). Hence, they are indicated further on as Cluster N (for Cluster 1 with thermally neutral data), Cluster W (for Cluster 2 with warm data), and Cluster C (for Cluster 3 with cold data).

Table 2 reports the daily average data measured in the monitored periods about temperature $\left(\mathrm{T},{ }^{\circ} \mathrm{C}\right)$, relative humidity $(\mathrm{RH}$, $\%$ ), and the calculated THI both inside the barn (internal microclimate) and outside the barn (external weather conditions) per farm and cluster. Besides, the differences between inside and outside the barn are shown with deltaT $\left({ }^{\circ} \mathrm{C}\right)$, deltaRH $(\%)$, and deltaTHI.

Regarding the THI in the barn, in all the analysed farms, the average value for Cluster W (i.e., cluster with observations of warm days) exceeded the threshold for welfare cattle conditions, set at 72 (Das et al., 2016). Primarily, this occurred in farms A and

Table 2. Daily means and standard deviations for the monitored periods for temperature $\left(\mathrm{T} ;{ }^{\circ} \mathrm{C}\right)$, relative humidity $(\mathrm{RH}$; $\%)$, and temperature-humidity index (THI) in the barn (microclimate) and outside the barn (external conditions) for the 8 farms and 3 clusters. The differences between inside and outside are shown as deltaT $\left({ }^{\circ} \mathrm{C}\right)$, deltaRH $(\%)$, and deltaTHI.

\begin{tabular}{|c|c|c|c|c|c|c|c|c|c|c|}
\hline \multirow[t]{2}{*}{ Cluster } & \multirow[t]{2}{*}{ Farm } & \multicolumn{3}{|c|}{ Internal microclimate } & \multicolumn{3}{|c|}{ External weather conditions } & \multirow[b]{2}{*}{ deltaT $\left({ }^{\circ} \mathrm{C}\right)$} & \multirow{2}{*}{$\begin{array}{c}\text { Difference } \\
\text { deltaRH (\%) }\end{array}$} & \multirow[b]{2}{*}{ deltaTHI } \\
\hline & & $\mathrm{T}\left({ }^{\circ} \mathrm{C}\right)$ & RH (\%) & THI & $\mathrm{T}\left({ }^{\circ} \mathrm{C}\right)$ & RH (\%) & THI & & & \\
\hline \multirow[t]{9}{*}{ N } & A & $17.7 \pm 3.9$ & $68.5 \pm 12.2$ & $63 \pm 5.4$ & $15 \pm 3.3$ & $78.6 \pm 21.4$ & $59.4 \pm 4.3$ & $2.6 \pm 1.6$ & $-10.1 \pm 14$ & $3.7 \pm 2.6$ \\
\hline & B & $17.3 \pm 4.2$ & $68.7 \pm 10$ & $62.6 \pm 5.9$ & $15.8 \pm 3.7$ & $73.1 \pm 14.3$ & $60.6 \pm 5$ & $1.5 \pm 1.3$ & $-4.5 \pm 8.2$ & $2 \pm 1.9$ \\
\hline & $\mathrm{C}$ & $16.3 \pm 3.9$ & $71.1 \pm 13.8$ & $60.9 \pm 5.7$ & $14.8 \pm 3.1$ & $81.5 \pm 19.5$ & $58.6 \pm 4.8$ & $1.6 \pm 2.2$ & $-10.4 \pm 11.5$ & $2.3 \pm 3.3$ \\
\hline & D & $16.2 \pm 3.7$ & $70.8 \pm 13.1$ & $60.8 \pm 5.5$ & $14.7 \pm 3.2$ & $80.8 \pm 19.7$ & $58.5 \pm 4.8$ & $1.6 \pm 2$ & $-10 \pm 10.6$ & $2.3 \pm 2.9$ \\
\hline & E & $15.7 \pm 4.4$ & $62.7 \pm 14.4$ & $60.3 \pm 6$ & $13.5 \pm 3.4$ & $76.8 \pm 23.7$ & $56.8 \pm 4.9$ & $2.3 \pm 2.2$ & $-14.1 \pm 11.8$ & $3.5 \pm 3.4$ \\
\hline & $\mathrm{F}$ & $15.8 \pm 4.4$ & $63.4 \pm 11.9$ & $60.3 \pm 6.1$ & $13.3 \pm 3.3$ & $75.9 \pm 24.5$ & $56.7 \pm 4.8$ & $2.5 \pm 2.1$ & $-12.6 \pm 15.7$ & $3.6 \pm 3.4$ \\
\hline & G & $15.5 \pm 2.7$ & $68.2 \pm 16.6$ & $59.7 \pm 3.7$ & $14 \pm 2.8$ & $78.6 \pm 23.6$ & $57.5 \pm 4.2$ & $1.4 \pm 1.8$ & $-10.5 \pm 10.3$ & $2.2 \pm 2.6$ \\
\hline & $\mathrm{H}$ & $14.9 \pm 3$ & $66.1 \pm 14.7$ & $58.9 \pm 4.1$ & $14 \pm 2.8$ & $79 \pm 23.5$ & $57.5 \pm 4.2$ & $1 \pm 2$ & $-12.9 \pm 17.8$ & $1.4 \pm 3$ \\
\hline & Mean \pm SD & $16 \pm 3.8$ & $67.3 \pm 14.2$ & $60.5 \pm 5.3$ & $14.3 \pm 3.2$ & $78.2 \pm 22$ & $58 \pm 4.7$ & $1.7 \pm 2$ & $-10.9 \pm 13.4$ & $2.5 \pm 3$ \\
\hline \multirow[t]{9}{*}{ W } & A & $27.8 \pm 4$ & $59 \pm 9.4$ & $76.6 \pm 4.8$ & $26.6 \pm 4.1$ & $60.9 \pm 15.1$ & $74.9 \pm 4.7$ & $1.3 \pm 2.1$ & $-1.9 \pm 10.5$ & $1.7 \pm 2.1$ \\
\hline & B & $26.8 \pm 3.9$ & $62.9 \pm 8.8$ & $75.8 \pm 5.4$ & $27.8 \pm 4.4$ & $53.4 \pm 11.1$ & $75.9 \pm 5.1$ & $-1 \pm 2$ & $9.5 \pm 7.2$ & $-0.1 \pm 2$ \\
\hline & C & $24.4 \pm 2.9$ & $70 \pm 12.7$ & $73 \pm 4.2$ & $24.5 \pm 3.8$ & $66.9 \pm 15.9$ & $72.5 \pm 4.4$ & $-0.1 \pm 2.9$ & $3.1 \pm 11$ & $0.5 \pm 3.5$ \\
\hline & D & $24.1 \pm 3.1$ & $68.6 \pm 11.5$ & $72.3 \pm 4.1$ & $24.4 \pm 3.7$ & $67.3 \pm 15.6$ & $72.4 \pm 4.4$ & $-0.3 \pm 2.5$ & $1.3 \pm 10.1$ & $-0.1 \pm 2.9$ \\
\hline & E & $24.7 \pm 3$ & $62.8 \pm 13.1$ & $72.7 \pm 3.8$ & $25.1 \pm 4.1$ & $63.6 \pm 19.7$ & $72.9 \pm 4.5$ & $-0.4 \pm 2.7$ & $-0.7 \pm 12.2$ & $-0.2 \pm 3$ \\
\hline & $\mathrm{F}$ & $24.9 \pm 3$ & $66.1 \pm 14.6$ & $73.3 \pm 3.8$ & $25.2 \pm 4$ & $63 \pm 19.7$ & $73 \pm 4.4$ & $-0.3 \pm 2.4$ & $3.1 \pm 10.9$ & $0.3 \pm 2.7$ \\
\hline & G & $25.9 \pm 3.4$ & $68.2 \pm 12.9$ & $74.8 \pm 4$ & $25.3 \pm 4.3$ & $73 \pm 22.4$ & $73.9 \pm 4.5$ & $0.6 \pm 2.7$ & $-4.8 \pm 14.6$ & $0.9 \pm 2.8$ \\
\hline & $\mathrm{H}$ & $26 \pm 3.3$ & $66.8 \pm 12.7$ & $74.9 \pm 3.9$ & $25.3 \pm 4.3$ & $73.1 \pm 22.4$ & $73.9 \pm 4.5$ & $0.7 \pm 2.9$ & $-6.2 \pm 15.9$ & $0.9 \pm 3$ \\
\hline & Mean \pm SD & $25.6 \pm 3.5$ & $65.4 \pm 12.5$ & $74.1 \pm 4.5$ & $25.6 \pm 4.2$ & $64.7 \pm 18.9$ & $73.7 \pm 4.7$ & $0 \pm 2.6$ & $0.8 \pm 12.5$ & $0.5 \pm 2.8$ \\
\hline \multirow[t]{9}{*}{$\mathrm{C}$} & A & $5.4 \pm 4.6$ & $70.5 \pm 14$ & $44.1 \pm 7$ & $1.5 \pm 2.4$ & $85.5 \pm 19.2$ & $36.4 \pm 5.3$ & $3.9 \pm 4.3$ & $-15 \pm 18.8$ & $7.6 \pm 7.3$ \\
\hline & B & $5.4 \pm 4.5$ & $69.8 \pm 13.8$ & $44.1 \pm 6.7$ & $2.3 \pm 2.3$ & $80.3 \pm 16.3$ & $38.4 \pm 4.8$ & $3.1 \pm 4.3$ & $-10.5 \pm 17.8$ & $5.7 \pm 7.3$ \\
\hline & C & $5 \pm 2.5$ & $78.4 \pm 6.4$ & $43.1 \pm 4.1$ & $2.6 \pm 3.3$ & $88.8 \pm 12.2$ & $37.9 \pm 6.3$ & $2.4 \pm 1.5$ & $-10.4 \pm 8.2$ & $5.2 \pm 3.3$ \\
\hline & D & $5.4 \pm 2.6$ & $75.7 \pm 7.5$ & $43.9 \pm 4.3$ & $2.6 \pm 3.3$ & $88.7 \pm 12.3$ & $37.9 \pm 6.3$ & $2.8 \pm 1.3$ & $-13.1 \pm 7.4$ & $6 \pm 3$ \\
\hline & E & $4.5 \pm 2.9$ & $78.8 \pm 7.6$ & $42.1 \pm 5$ & $3.1 \pm 3$ & $96.4 \pm 8.6$ & $37.8 \pm 5.7$ & $1.4 \pm 1.1$ & $-17.6 \pm 5.8$ & $4.3 \pm 2.3$ \\
\hline & $\mathrm{F}$ & $5.9 \pm 2.4$ & $75.5 \pm 5$ & $44.8 \pm 3.8$ & $3 \pm 3$ & $96.4 \pm 8.6$ & $37.8 \pm 5.7$ & $2.9 \pm 1.1$ & $-20.9 \pm 5.7$ & $7 \pm 2.6$ \\
\hline & G & $7.3 \pm 4.3$ & $69.5 \pm 14.4$ & $46.9 \pm 6.5$ & $2.8 \pm 2.8$ & $90.6 \pm 11.6$ & $38 \pm 5.3$ & $4.5 \pm 3.3$ & $-21.1 \pm 9.7$ & $8.9 \pm 4.8$ \\
\hline & $\mathrm{H}$ & $6.8 \pm 4.1$ & $71.1 \pm 13.4$ & $46.1 \pm 6.2$ & $2.8 \pm 2.8$ & $90.7 \pm 11.6$ & $38 \pm 5.3$ & $4 \pm 3.5$ & $-19.5 \pm 9.8$ & $8.1 \pm 5.1$ \\
\hline & Mean \pm SD & $5.8 \pm 3.8$ & $73.2 \pm 11.9$ & $44.6 \pm 5.9$ & $2.5 \pm 2.9$ & $89.2 \pm 14.1$ & $37.8 \pm 5.6$ & $3.3 \pm 3.2$ & $-16 \pm 12.5$ & $6.8 \pm 5.2$ \\
\hline
\end{tabular}

SD, standard deviation. 
B (THI equal to 76.6 and 75.8, respectively), where also the external weather conditions were undesired. Regarding the other farms, high $\mathrm{RH}$ in the barn was observed in farms $\mathrm{D}, \mathrm{G}$, and $\mathrm{H}$, where the installed sprinkler systems affected the internal air humidity. Also, farm $\mathrm{C}$ had high $\mathrm{RH}$, but it was not equipped with sprinkler/fogging systems; therefore, this result was due to insufficient forced ventilation or capability of achieving sufficient air exchange rates.

Regarding the other clusters: i) temperature in the cluster, $\mathrm{C}$ ranged between $4.5^{\circ} \mathrm{C}-7.3^{\circ} \mathrm{C}$ and in cluster $\mathrm{N}$ between $14.9^{\circ} \mathrm{C}$ $17.7^{\circ} \mathrm{C}$; ii) internal $\mathrm{RH}$ in cluster $\mathrm{C}$ ranged between $70-79 \%$ and in cluster $\mathrm{N}$ between $63-71 \%$; iii) internal THI was on average 42.146.9 in cluster $\mathrm{C}$ and 58.9-63.0 in cluster $\mathrm{N}$.

Focusing on deltaTHI, 5 out of 8 farms showed values higher than zero in Cluster W, meaning that the internal THI exceeded the external one. This is an expected result due to radiant heat and the release of animals' metabolic heat (Berman, 2019; Polsky and von Keyserlingk, 2017). DeltaTHI was close to zero in most farms, except for farms $\mathrm{A}, \mathrm{G}$, and $\mathrm{H}$ that had wider differences (i.e., the internal THI exceeds the external one considerably), which can be a signal for a more alarming microenvironment for cows than other farms. Farms B, D, and E had an average deltaTHI in Cluster W slightly lower than zero; therefore, the barn structure and the cooling systems also helped reduce the internal THI, reducing relative humidity and temperature through air exchanges and cooling animals' bodies. The fact that the external THI was measured with weather stations not directly located on the farm may have affected the assessment of differences between inside and outside the barns; however, the weather stations were very close to the farms, so the differences in temperature and relative humidity within such a short distance were assumed negligible.

Figure 1 reports the distinction per cluster and farm of the relative contribution of the 6 THI classes to the barn microclimate.

In cluster $\mathrm{W}$, farms $\mathrm{A}, \mathrm{B}, \mathrm{G}$, and $\mathrm{H}$ highlighted the most frequent emergence of undesired THI values. These farms had $80 \%$,
$72 \%, 76 \%$ and $78 \%$ of THI data above 72 (classes $72<\mathrm{THI}<=75$, $75<\mathrm{THI}<=78$ and THI $>78$ ), respectively. Of these, farms A and B had $63 \%$ of data in the two worst classes $(75<=\mathrm{THI}<78$ and THI $>=78$ ), while farms $\mathrm{G}$ and $\mathrm{H}$ had $48 \%$ for both. Farms C, D, E, and $\mathrm{F}$ had much better conditions, with about $26-33 \%$ of data in the THI classes above 75 .

All farms showed difficulties in maintaining acceptable THI values in cluster $\mathrm{W}$, and in some cases, this occurred in cluster $\mathrm{N}$ $(<10 \%$ of data). Besides the THI, the consecutive hours in which THI is above the threshold of 72 are even more important (Allen et al., 2015) because this condition compromises cows' ability to dissipate excess body heat, finally leading to reduced feed intake, milk production, reproductive efficiency, health and welfare problems (Das et al., 2016). About this aspect, farms A and B had constantly a THI $>=72$ for the whole week observed in the warm survey, thus even at night, no relief was observed. The other farms had, on average: farm C $14.3 \pm 12.7$ consecutive hours of THI $>=72$, farm D 14.3 $\pm 4.9 \mathrm{~h}$, farm E $15.3 \pm 3.4 \mathrm{~h}$, farm F 14.0 $\pm 6.0 \mathrm{~h}$, farm G $22.8 \pm 23.2 \mathrm{~h}$, and farm $\mathrm{H} 20.4 \pm 22.7 \mathrm{~h}$.

From the assessment on the microclimate, farms A, B, G, and $\mathrm{H}$ had the most critical conditions for THI. This could be due to the high external temperatures but mainly to the insufficient response of the structure to external conditions (upper opening and related dimension, insulation materials, height of the barn, and roof inclination).

\section{Statistical effects of structural and environmental aspects}

Farms were analysed considering microclimate and structural aspects to understand if and how the barn structure effectively affected the microclimate. In particular, the GLM procedure was carried out to develop a model that predicted the THI internal to the barn based on structural parameters. The 3 clusters based on external THI (clusters N, W, and C) were used as input to the

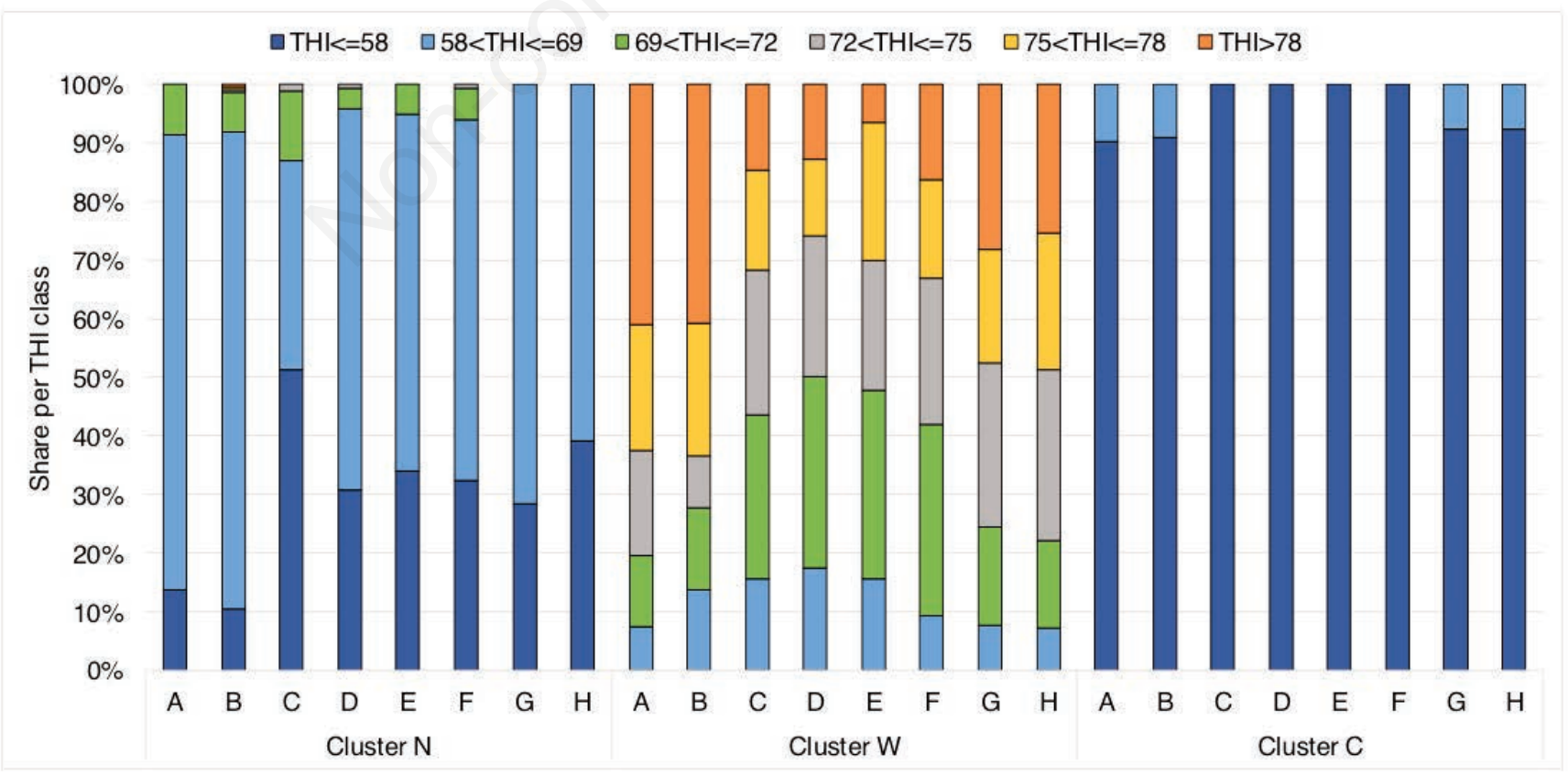

Figure 1. Contribution of each class of internal temperature-humidity index (THI) per cluster (N, W, and C) and per farm (A to H) to internal THI. 
model, together with the effects of lateral openings, roof height, forced ventilation, and orientation.

The model was highly significant $(\mathrm{P}<0.0001)$ and had a coefficient of determination $\mathrm{R} 2=0.85$. All parameters introduced in the model were significant. Model estimates and standard errors are reported in Table 3 for all parameters used. Those parameters whose estimate resulted equal to zero were not included in the table, and they were: 'Cluster C', 'Total lateral openings', 'Medium roof height', 'Forced ventilation feed+rest', and 'Orientation: NW-SE'.

Table 4 reports the LSMeans of the effects included in the model.

In cluster $\mathrm{W}$, the THI in the barn is 29.7 points higher than the intercept, while cluster $\mathrm{N}$ is 15.9 points higher than the intercept. In cluster $\mathrm{C}$, no increase/reduction with respect to the intercept is observed. Furthermore, interesting findings emerge from the structural aspects: if partial lateral openings are present, internal THI is strongly affected, resulting in 4.36 points higher than the intercept; therefore, introducing total lateral openings allows maintaining better internal THI. Similarly, if the barn has a low roof height $(<7$ $\mathrm{m})$, then the internal THI is 1.98 points higher than the intercept, therefore, also, in this case, higher roof heights improve air exchanges and permit to avoid increasing the internal THI. Respect to the orientation, the E-W option is the best since internal THI results in -2.35 points than the intercept and the NE-SW orientation achieves -1.90 points. Considering the ventilation system, the most interesting results are achieved with the forced ventilation introduced in the feeding area that reduces THI by -1.98 points with respect to the intercept, and the one in the lying area that achieves -3.44 . Thus, introducing the proper forced ventilation in one of the 2 areas of the barn results sufficient to improve THI.

In general, the lack of openings and proper orientation, and small roof height are the main structural aspects that influence thermal buoyancy. Natural and forced ventilation are key aspects to keep THI below the threshold of heat stress and to bring relief to cows' perceived temperature (Bohmanova et al., 2007; Allen et al., 2015; Das et al., 2016; Polsky and von Keyserlingk, 2017; Berman, 2019). Therefore, studying the optimal application of ventilation is fundamental, especially thinking about the predicted future increase of temperatures and heatwave events (Hempel et al., 2018). In literature, few studies focus on the evaluations about

Table 3. Model with parameters, estimates, and standard error for the model carried out with the generalized linear model (GLM) procedure.

\begin{tabular}{lcc} 
Parameter & Estimate & S.E. \\
Intercept & 43.17 & 0.26 \\
Cluster N & 15.94 & 0.20 \\
\hline Cluster W & 29.71 & 0.19 \\
Partial lateral openings & 4.36 & 0.61 \\
\hline Low roof height & 1.98 & 0.30 \\
Forced ventilation - feeding & -1.98 & 0.52 \\
\hline Forced ventilation - resting & -3.44 & 0.41 \\
Orientation EW & -2.35 & 0.44 \\
\hline Orientation NE-SW & -1.90 & 0.32
\end{tabular}

The parameters for which the estimate value is zero are not reported (i.e., 'Cluster C', 'Total lateral openings', 'Medium roof height', 'Forced ventilation feed+rest', 'Orientation: NW-SE'. S.E., standard error. barn structures and the building aspects of dairy cattle barns, to the authors' knowledge. Instead, much research has been done on forced ventilation, its modelling, and the cooling effects on animals, thus primarily focusing on their behavioural and productive responses (Honig et al., 2012; Porto et al., 2017; Pinto et al., 2019).

Regarding the LSMeans, the internal THI values are reported for all evaluated effects, each of which presented statistical differences among each other $(\mathrm{P}<0.0001)$, except for the orientation $\mathrm{E}$ $\mathrm{W}$ and NE-SW $(\mathrm{P}=0.68)$.

\section{General remarks on barn structures}

A proper barn structure is fundamental for achieving good microclimatic conditions to benefit animals' health, welfare, and productivity (Halachmi et al., 2019; Lovarelli et al., 2020a). In particular, the importance of the structural characteristics that favour thermal buoyancy and generally natural and forced ventilation as well as of good air exchange rates was confirmed by this study.

The best condition can be achieved with a properly designed barn that allows optimal natural ventilation, which is also costeffective. However, in climatic conditions such as those in Northern Italy, forced ventilation is becoming more important due to heatwaves, sensitive high-productive animals, and increased welfare requirements (Berman, 2019). In Hempel et al. (2018), for example, authors studied the mid-term heat stress risk in dairy cattle farms in Germany and Spain and reported an increase in heat stressing events and in prolonged periods with heat stressing conditions for the future, especially for the Mediterranean area. A second important advantage of forced ventilation is its role in improving indoor air quality (e.g., ammonia, methane), which can also be important for animals' health in some barn structures (Firfiris et al., 2019). Forced ventilation coupled with cooling systems such as sprinklers or fogging can even increase animals' comfort. In any case, the literature suggests that forced ventilation must be well balanced in the different parts of the barn; otherwise, cows may show behavioural alterations with undesired results (Honig et al., 2012; Porto et al., 2017). Among the main ones can be listed the preference of areas where ventilation is present (CIGR, 2014), at the expense of other areas (e.g., they may tend to eat and stand,

Table 4. LSMeans of the effects included in the generalized linear model (GLM) procedure.

\begin{tabular}{lcc}
\hline Effect & & LSMeans for internal THI \\
Cluster & $\mathrm{N}$ & $59.1^{* * *}$ \\
& $\mathrm{~W}$ & $72.8^{* * *}$ \\
\multirow{4}{*}{ Lateral openings } & $\mathrm{C}$ & $43.1^{* * *}$ \\
& Partial & $60.5^{* * *}$ \\
& Total & $56.2^{* * *}$ \\
\hline Roof height & Low & $59.3^{* * *}$ \\
& Medium & $57.3^{* * *}$ \\
Forced ventilation & Feed & $58.2^{* * *}$ \\
& Lying & $56.7^{* * *}$ \\
& Feed+lying & $60.1^{* * *}$ \\
\hline Orientation & E-W & 57.4 (n.s.) \\
& NE-SW & 57.9 (n.s.) \\
& NW-SE & $59.8^{* * *}$ \\
\hline
\end{tabular}

***Statistically significant difference among effects; (n.s.), the difference between these two options in the orientation effect is not statistically significant. THI, temperature-humidity index. 
reducing the lying and rumination time or they lie down too much and not eat).

For these reasons, the continuous real-time monitoring of barns is becoming very important since it is evident that the more is known and quantified, the easier it is to understand what happens and improve the managerial activities and decision-making process (CIGR, 2014). In particular, farmers can understand the cows' responses to the microclimate and make decisions to improve comfort, welfare, health, and productivity. In this context, Precision Livestock Farming (PLF) approach and its further achievements can represent the proper way towards holistic monitoring of livestock farming (Halachmi et al., 2019; Arcidiacono et al., 2020; Tassinari et al., 2021), especially considering the possibility of automatically starting or regulating the devices in the barns, such as the forced ventilation. In this regard, future research could focus on integrating the microclimatic measures with other automatic devices in the barns to allow the objective evaluation of animals' living conditions and improve the management, structures, and equipment of dairy barns with rapid and automatic interventions.

\section{Conclusions}

This study studied the relation between barn structure and microclimate in 8 dairy cattle barns selected in Northern Italy. The results showed that both structural aspects and natural and forced ventilation helped improve the internal THI of the barns and, therefore, the animals' comfort. In particular, all the farms showed some difficulties responding to heat stress. The barn characteristics affected the internal microclimate, with the warm season being the more critical period in the study area. The structures examined could not mitigate the external conditions; therefore, the need to improve the efficiency of the combination of structural aspects such as lateral openings, ridge height, forced ventilation, and cooling systems emerged. In fact, the less efficient farms were those in which the natural ventilation was found limited. In these conditions, the installed forced ventilation and cooling systems mitigated the lack of the design for climate control but could not reduce the internal THI to acceptable values. Moreover, the results also confirm the importance of appropriate ventilation during the whole year to avoid the excessive increase of internal humidity and THI even in temperate conditions.

\section{References}

Allen J.D., Hall L.W., Collier R.J., Smith J.F. 2015. Effect of core body temperature, time of day, and climate conditions on behavioral patterns of lactating dairy cows experiencing mild to moderate heat stress. J. Dairy Sci. 98:118-27.

Arcidiacono C., Mancino M., Porto S.M.C. 2020. Moving meanbased algorithm for dairy cow's oestrus detection from uniaxial-accelerometer data acquired in a free-stall barn. Comp. Electron. Agr. 175:105498.

ASABE. 2006. Design of ventilation systems for poultry and livestock shelters. pp 652-670 in Standards 2006 American Society of Agri-cultural and Biological Engineers (53rd Edition), St. Joseph, MI, USA.

Bar D., Kaim M., Flamenbaum I., Hanochi B., Toaff-Rosenstein R.L. 2019. Technical note: Accelerometer-based recording of heavy breathing in lactating and dry cows as an automated measure of heat load. J. Dairy Sci. 102:3480-86.

Bellingeri A., Cabrera V., Gallo A., Liang D., Masoero F. 2019. A survey of dairy cattle management, crop planning, and forages cost of production in Northern Italy. Ital. J. Anim. Sci. 18:786-98.

Berman A. 2019. An overview of heat stress relief with global warming in perspective. Int. J. Biometeorol. 63:493-8.

Bohmanova J., Misztal I., Cole J.B. 2007. Temperature-humidity indices as indicators of milk production losses due to heat stress. J. Dairy Sci. 90:1947-56.

CIGR. 2014. The design of dairy co and replacement heifer housing. Report of the CIGR Section II Working Group n. 14 - cattle housing.

Das R., Sailo L., Verma N., Bharti P., Saikia J. 2016. Impact of heat stress on health and performance of dairy animals: a review. Veterinary World 9:260-8.

De Paepe M., Pieters J.G., Cornelis W.M., Gabriels D., Merci B., Demeyer P. 2012. Airflow measurements in and around scale model cattle barns in a wind tunnel: effect of ventilation opening height. Biosyst. Eng. 113:22-32.

Fernández M.E., Mariño R.A., Carreira X.C. 2008. Relationship between layout and timber structures in freestall dairy cattle barns: influence of internal features. Biosyst. Eng. 100:266-80.

Ferraz P.F.P., Ferraz G.A.e.S., Leso L., Klopčič M., Barbari M., Rossi G. 2020. Properties of conventional and alternative bedding materials for dairy cattle. J. Dairy Sci. 103:8661-74.

Firfiris V.K., Martzopoulou A.G., Kotsopoulos T.A. 2019. Passive cooling systems in livestock buildings towards energy saving: A critical review. Energ. Buildings 202:109368.

Halachmi I., Guarino M., Bewley J., Pastell M. 2019. Smart animal agriculture: application of real-time sensors to improve animal well-being and production. Annu. Rev. Anim. Biosci. 7:403-25.

Hempel S., Menz C., Pinto S., Galán E., Janke D., Estellés F., Müschner-Siemens T., Wang X., Heinicke J., Zhang G., Amon B., del Prado A., Amon T. 2019. Heat stress risk in European dairy cattle husbandry under different climate change scenarios-uncertainties and potential impacts. Earth Syst. Dynam. 10:859-84.

Honig H., Miron J., Lehrer H., Jackoby S., Zachut M., Zinou A., Portnick Y., Moallem U. 2012. Performance and welfare of high-yielding dairy cows subjected to 5 or 8 cooling sessions daily under hot and humid climate. J. Dairy Sci. 95:3736-42.

ISTAT. 2021. Italian National Institute of Statistics. Available from: http://dati.istat.it/?lang=en Accessed: 13 Sept. 2021.

Lovarelli D., Bacenetti J., Guarino M. 2020a. A review on dairy cattle farming: Is precision livestock farming the compromise for an environmental, economic and social sustainable production? J. Clean Prod. 262:121409.

Lovarelli D., Finzi A., Mattachini G., Riva E. 2020b. A survey of dairy cattle behavior in different barns in Northern Italy. Animals 10:713.

Menconi M.E., Grohmann D. 2014. Model integrated of life-cycle costing and dynamic thermal simulation (MILD) to evaluate roof insulation materials for existing livestock buildings. Ener. Buildings 81:48-58.

Pinto S., Hoffmann G., Ammon C., Heuwieser W., Levit H., Halachmi I., Amon T. 2019. Effect of two cooling frequencies on respiration rate in lactating dairy cows under hot and humid climate conditions. Ann. Anim. Sci. 19:821-34.

Polsky L., von Keyserlingk M.A. 2017. Invited review: Effects of heat stress on dairy cattle welfare. J. Dairy Sci. 100:8645-57.

Porto S.M.C., D'Emilio A., Cascone G. 2017. On the influence of the alternation of two different cooling systems on dairy cow 
daily activities. J. Agr. Eng. 48:21-7.

Provolo G., Riva E. 2008. Influence of temperature and humidity on dairy cow behaviour in freestall barns. Agricultural and Biosystems Engineering for a sustainable world: Conference Proceedings, Hersonissos, Greece.

Tassinari P., Bovo M., Benni S., Franzoni S., Poggi M., Mammi L.M.E., Mattoccia S., Di Stefano L., Bonora F., Barbaresi A., Santolini E., Torreggiani D. 2021. A computer vision approach based on deep learning for the detection of dairy cows in free stall barn. Comp. Electron. Agr. 182:106030.

Van Iaer E., Tuyttens F.A.M., Ampe B., Sonck B., Moons C.P.H., Vandaele L. 2015. Effect of summer conditions and shade on the production. Animal 9:1547-58.

Vox G., Maneta A., Schettini E. 2016. Evaluation of the radiometric properties of roofing materials for livestock buildings and their effect on the surface temperature. Biosyst. Eng. 144:26-37. 